\title{
Uma análise da concentração na agroindústria canavieira em Minas Gerais (safras 2002/2003 a 2014/2015)
}

\author{
Tiago Rodrigo Fischer ${ }^{1}$ \\ Cristiane Fernanda Klein ${ }^{2}$ \\ Débora Cristina Kliemann ${ }^{3}$ \\ Pery Francisco Assis Shikida ${ }^{4}$
}

\begin{abstract}
Resumo:
Este artigo mensura e analisa a concentração na moagem de cana em Minas Gerais entre as safras 2002/2003 e 2014/2015. Para a análise dos dados, foram utilizados os $C R_{4}$ e $C R_{8}$, os índices de Hirschmann-Herfindahl, de Rosenbluth e Entropia de Theil. Em termos gerais, houve redução da concentração até a média móvel trianual 2010/20112012/2013, apontando para uma melhor condição de competitividade no mercado. Porém, a partir desse ponto há sinalização de um crescimento nessa concentração, revertendo a tendência até então apresentada.

Palavras-Chave: cana-de-açúcar; concentração; produção.
\end{abstract}

An analysis of the concentration in sugarcane agroindustry in Minas Gerais state (harvests 2002/2003 to 2014/2015)

\begin{abstract}
:
This article measures and analyzes the concentration in sugarcane milling in Minas Gerais between the harvests of 2002/2003 to 2014/2015. For the data analysis, were used the $C R_{4}$ e $C R_{8}$, rates of Hirschmann-Herfindahl, of Rosenbluth and Entropy Theil. Overall, there was a reduction of the concentration to three-year moving average 2010 / 2011-2012 / 2013, pointing to a better competitive condition in the market. However, from this point there are signs of an increase in that concentration, reversing the trend so far presented.
\end{abstract}

Keywords: sugar cane; concentration; production.

\section{Classificação JEL: Q02; L13}

1 Mestrando do Programa de Desenvolvimento Regional e Agronegócio da Universidade Estadual do Oeste do Paraná (UNIOESTE/Campus Toledo). Professor Assistente da Universidade Paranaense (UNIPAR/Unidade Toledo).E-mail: ti_fischer@hotmail.com

2 Mestranda do Programa de Desenvolvimento Regional e Agronegócio da Universidade Estadual do Oeste do Paraná (UNIOESTE/Campus Toledo). Pesquisadora do Grupo de Estudos em Desenvolvimento Regional e Agronegócio (GEPEC). E-mail: cristiane.fklein@gmail.com

3 Mestranda do programa de Desenvolvimento Regional e Agronegócio da Universidade Estadual do Oeste do Paraná (UNIOESTE/Campus Toledo). Professora colaboradora da Universidade Paranaense (UNIPAR/Unidade Toledo). E-mail: dkarquitetura@outlook.com

4 Doutor em Economia Aplicada pela ESALQ/USP. Professor Associado da Universidade Estadual do Oeste do Paraná (UNIOESTE). Bolsista de Produtividade em Pesquisa do CNPq. E-mail: peryshikida@hotmail.com 


\section{Introdução}

Este artigo mensura e analisa a concentração na produção agroindustrial canavieira em Minas Gerais entre as safras 2002/2003 e 2014/2015.

O Estado de Minas Gerais é um dos principais produtores de cana-de-açúcar do Brasil, chegando a representar quase $10 \%$ da produção na safra de 2014/2015 tanto de cana-de-açúcar como de açúcar e etanol, ficando atrás somente do Estado de São Paulo, que representa mais de 50\% do total da produção (União da Indústria de Cana-de-Açúcar - UNICA, 2016).

Minas Gerais apresenta 34 unidades produtoras, gerando aproximadamente 1.000 empregos formais. A área plantada é de 930 mil hectares de cana, gerando uma produção de 59 milhões de toneladas de cana-de-açúcar (safra 2014/2015). A produção de açúcar nessa safra foi de 3,2 milhões de toneladas, enquanto a produção de etanol (anidro e hidratado) chegou a 2,7 milhões de $\mathrm{m}^{3}$. Apesar desses números, o recorde de produção mineira ocorreu na safra anterior, quando a produção foi de 61 milhões de toneladas (UNICA, 2016). Tal queda ocorreu em função de uma severa seca observada em várias regiões produtoras.

Numa breve alusão ao período enfocado por este trabalho, em 2002, foi apresentado em plano nacional, o primeiro veículo com motor flex-fuel (que funciona com mais de um tipo de combustível e em quaisquer proporções), desenvolvido por empresas alemãs, e que começou a ser produzido em série a partir de março de 2003. Em consequência disso, o Brasil passou por uma nova expansão dos canaviais com o objetivo de oferecer, em grande escala, o etanol como combustível alternativo (KOHLHEPP, 2010; CHAGAS, 2014).

Além do aumento da produção do etanol, ocorreu também crescimento nas exportações de açúcar no período analisado. Conforme compilação feita entre dados da Associação de Produtores de Bioenergia do Estado do Paraná - ALCOPAR (2016) e UNICA (2016), em 2002, foram exportadas 13 milhões de toneladas de açúcar pelo Brasil, já na safra 2014/2015 essa monta atingiu 24 milhões de toneladas, um crescimento de $81,5 \%$.

Esses processos impactaram diretamente na produção canavieira (que passou a ter crescimentos anuais significativos), bem como nos preços da cana-de-açúcar. Como exemplo, o preço da cana-de-açúcar aumentou de $\mathrm{R} \$ 18,01$ a tonelada em janeiro de 2001, para $\mathrm{R} \$ 26,25$ em dezembro de 2003. Esse aspecto reforça a importância de se iniciar a presente análise na safra de 2002/2003, que pode ser considerada um ponto de inflexão para a agroindústria canavieira do País (Departamento de Economia Rural - DERAL, Secretaria da Agricultura e do Abastecimento SEAB, 2016).

Com feito, o movimento de fusões e aquisições de usinas passou a denotar outra dinâmica no cenário competitivo da agroindústria canavieira no Brasil, especialmente após o processo de desregulamentação setorial em que as leis de mercado passaram a vigorar, sendo extinto o paradigma subvencionista que existia nessa atividade desde 1933 e, mais recentemente, diante da forte crise que afetou essa economia (SIQUEIRA, 2013; SHIKIDA, 2014). Para Mello e Paulillo (2005, p.24), “[...] a estratégia de aquisições constitui-se numa busca por economias de escala, 
na redução de despesas por meio da integração das estruturas administrativas e de produção e uso racional de terras nas regiões tradicionais”.

Mas como estará a evolução da concentração da agroindústria canavieira em Minas Gerais? Hersen et al. (2011) analisaram a concentração na agroindústria canavieira mineira durante as safras 1996/1997 a 2005/2006; entretanto, transcorrida uma década (desde a última safra ora pontuada), modificações podem ter ocorrido nesse cenário considerado muito dinâmico. Nesse contexto, mediante evolução da produção canavieira em Minas Gerais, coloca-se o seguinte questionamento: da safra 2002/2003 para a safra 2014/2015, a produção de cana-de-açúcar passou a ter maior ou menor concentração?

Além dessa introdução, este trabalho apresenta mais três seções. A próxima seção apresenta uma concisa revisão de literatura sobre elementos da evolução na produção de cana-de-açúcar e seus derivados em Minas Gerais e no restante do Brasil. A seção três contempla o material e método, em seguida são apresentados os resultados e discussão derivados da pesquisa. Por fim, a seção cinco apresenta as considerações finais.

\section{Revisão de literatura}

A produção de cana-de-açúcar foi uma atividade importante para a economia brasileira em diferentes períodos da história, com destaque para o Ciclo do Açúcar (1530 até o século XVII) (SHIKIDA, 1997; SIQUEIRA; CASTRO JÚNIOR, 2013). E, quando se trata da regulação da produção canavieira no Brasil, algumas fases se mostram significativas.

Um marco para a produção canavieira brasileira foi a criação do Instituto do Açúcar e do Álcool (IAA) em 1933. Sua criação teve como objetivo defender as empresas açucareiras e alcooleiras nacionais mediante a utilização de uma série de mecanismos direcionados para garantir, dentre outras coisas, o equilíbrio interno entre as safras anuais de cana-de-açúcar e o consumo dos seus principais produtos (SHIKIDA, 1997).

A fase marcada como expansão diferenciada e as contradições do "desenvolvimento equilibrado” estende-se de 1947-1949 a 1968-1969. Nesse período, houve uma forte intervenção do Estado de uma forma mais direta, estabelecendo normas para que houvesse um equilíbrio na produção canavieira entre as regiões brasileiras. Ainda assim, o Centro-Sul passou a superar as produções do Norte-Nordeste já na safra 1949-1950, chegando a ser três vezes maior na safra 1965-1966 (SHIKIDA, 2014).

A fase que se estabelece do período de 1969-1970 a 1974-1975 marcou a consolidação da produção integrada, bem como uma crise do setor açucareiro. Nesse período, uma ação impactante à produção ocorreu, mais precisamente em 1971, com a instituição da política de subsídio de equalização de custo imposta pelo governo para cobrir as diferenças entre os custos de produtores no Norte-Nordeste e Centro-Sul, dando continuidade ao forte intervencionismo estatal e ao modelo de sobrevivência já estabelecido (LIMA, 1992). 
Em meio a uma crise do petróleo iniciada em 1973, em 1975 foi implantado o Programa Nacional do Álcool (Proálcool) que, desse ano até 1995, foi o "carro chefe" da agroindústria canavieira. Esse programa teve por objetivo estimular a produção de etanol, tido como combustível nacional, o que contribuiu para o crescimento da produção canavieira no Brasil (SANTOS et al., 2016).

Não obstante, na década de 1980 houve queda no preço do petróleo, o que provocou uma crise na produção de etanol (nomenclatura utilizada atualmente para o álcool combustível), posto que alguns concorrentes (notadamente, gasolina e diesel) voltaram a ter preços mais baixos vis-à-vis o etanol. Essa crise só não foi maior para a agroindústria canavieira porque o preço do açúcar estimulou a produção dessa commodity. Contudo, a década de 1990 viria apresentar um novo contexto institucional denominado de desregulamentação do setor sucroalcooleiro, em que o Estado diminuiu seus mecanismos de intervenção no setor, atuando mais como coordenador do que interventor (VIAN, 2003).

Essa desregulamentação afetou fortemente a agroindústria canavieira brasileira pós-1990, e também contribuiu para ampliar a competitividade e eficiência do etanol brasileiro, haja vista que, com a diminuição do controle estatal, as usinas e destilarias tiveram que se adaptar ao livre mercado e caminhar sem os incentivos, subsídios e a coordenação do Estado que eram aplicados anteriormente. Dessa forma, os agentes econômicos passaram a desenvolver novas competências visando gerar vantagens técnicas. Já do ponto de vista institucional, a criação da CIDE (Contribuição de Intervenção no Domínio Econômico) tem contribuído para garantir a competitividade do etanol em relação à gasolina, ou seja, manter a atividade de forma sustentável (PAULILLO et al., 2007).

Ao final da década de 1990, a agroindústria canavieira no Brasil passou por uma nova crise, com queda no consumo de etanol e preços de exportação do açúcar permanecendo em níveis considerados baixos (entre US\$150 e US\$200 por tonelada). Além disso, o número de unidades produtivas também sofreu oscilações durante essa década, e as perspectivas apontavam para um cenário desfavorável, mormente, em virtude da diminuição da frota de carros movida a etanol (BACCARIN; GEBARA; FACTORE, 2009).

No início dos anos 2000, um dos aspectos mais relevantes na influência da produção agroindustrial canavieira foi a nova tecnologia de motores flex-fuel para veículos leves no Brasil. Isso possibilitou maior demanda por etanol, ao mesmo tempo em que esse combustível passava a ser mais atrativo devido aos crescimentos graduais do preço do barril de petróleo (que atingiu US\$ 132 o barril - julho de 2008). Não obstante, nos últimos anos, o que se tem verificado é o reverso, ou seja, o preço do barril do petróleo tem atingido patamares baixos (US\$ 60,55 o barril dezembro de 2014) ${ }^{5}$.

Todo esse processo de evolução da agroindústria canavieira impactou não só Minas Gerais, como também todo o contexto nacional. No estado, a produção de cana-de-açúcar teve início somente a partir do século XVIII, quando a cultura já não era tão importante para a economia do País. Assim, surgiu como um "apêndice" de

5 Baseado em dados do Banco Mundial (2016). 
uma nova atividade econômica estadual, sendo a mais importante, à época, a extração de ouro e pedras preciosas (SIQUEIRA, 2013).

O crescimento expressivo da produção canavieira em Minas Gerais ocorreu a partir de 1975 com a implantação do Proálcool, sendo que, até 1985, a produção de etanol cresceu consideravelmente, enquanto a produção de açúcar não logrou o mesmo êxito. Esse crescimento vai até a década de 1990, período da desregulamentação do setor, e se dá com ainda mais intensidade após o ano de 2000 quando surge a tecnologia flex-fuel. Quanto à produção de açúcar, o estado obteve uma taxa geométrica de crescimento de $9,73 \%$ entre as safras 1990/1991 e 2011/2012. A produção de etanol também aumentou, nesse período, 388,45\% (SIQUEIRA; CASTRO JÚNIOR, 2013; UNICA, 2016).

No trabalho de Hersen et al. (2011) verificou-se uma concentração da produção agroindustrial canavieira no período de 1996/1997 a 2005/2006, em razão do crescimento das empresas de grande porte e do perfil do mercado do setor, que é de oligopólio concentrado. Como observado na Figura 1, após o ano de 2003, houve uma expressiva concentração de unidades produtivas da agroindústria canavieira na região do Triângulo Mineiro, onde, no ano de 2010, estavam instaladas 21 unidades produtivas.

Figura1 - Mapa de localização das unidades produtivas da agroindústria canavieira em Minas Gerais, instaladas após 2003 - posição em 2010

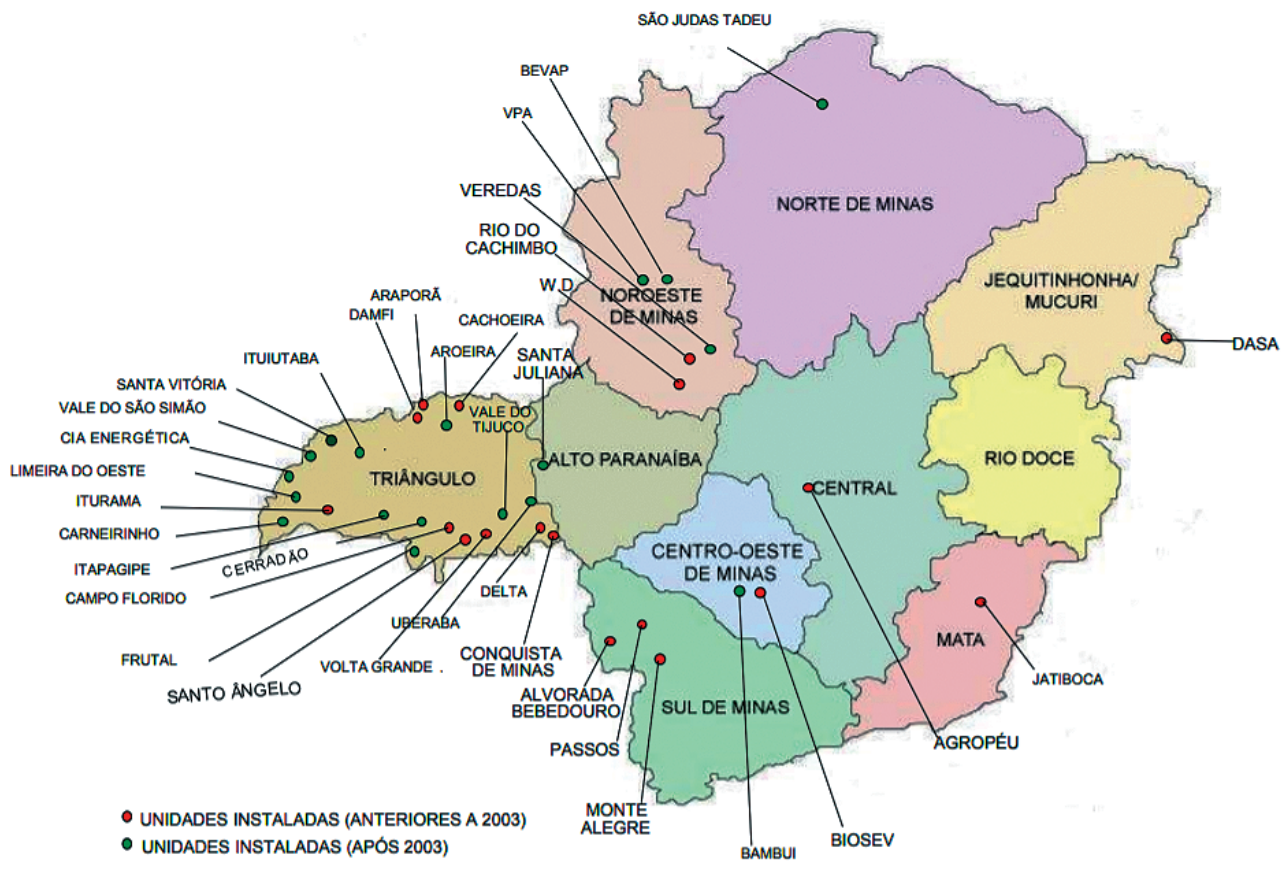

Fonte: SIAMIG/SINDAÇÚCAR-MG, 2010. 
Essa característica pode ser melhor visualizada na Figura 2, que representa a produção de cana-de-açúcar por região do estado mineiro, porém na safra 20142015, mostrando que a região do Triângulo, nessa safra, abarcou $71 \%$ do total da cana-de-açúcar, $94 \%$ do etanol e $80 \%$ da produção de açúcar, enquanto outras regiões do estado não chegam a $10 \%$ da participação.

Figura 2 - Produção por Mesorregião de Minas Gerais - safra 2014-2015

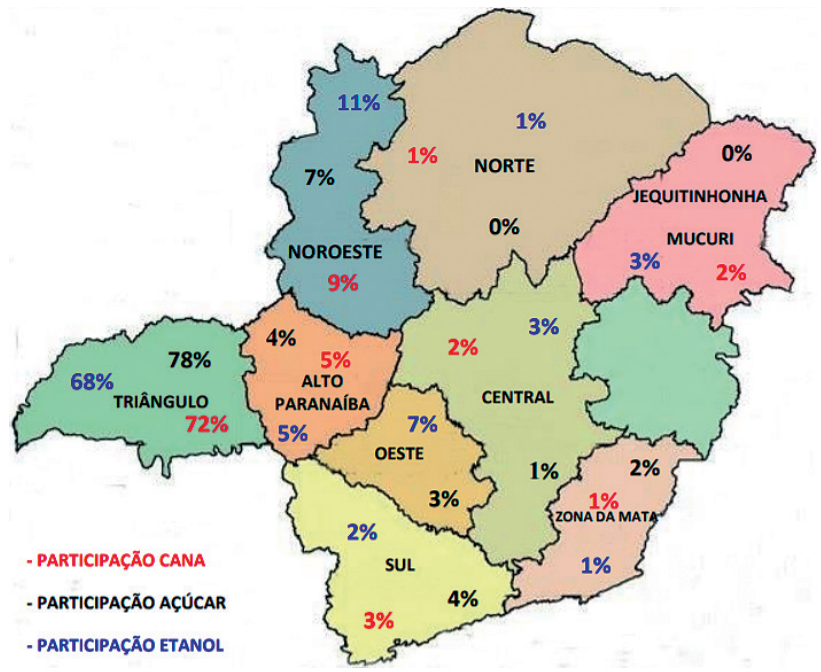

Fonte: SIAMIG/SINDAÇÚCAR-MG, 2015.

Esse cenário ocorre em virtude de o Triângulo Mineiro localizar-se em uma das regiões consideradas propícias à produção de cana-de-açúcar, o que envolve condições climáticas, tipo de solo (Latossolo, com áreas mais planas na forma de terra "solta") e bacia hidrográfica. Outro aspecto importante é a infraestrutura de armazenamento e logística adequada, devido à proximidade com São Paulo, facilitando o transporte até o porto. Além do Triângulo, a região do Alto Paranaíba também é beneficiada por esses elementos (SIQUEIRA; CASTRO JÚNIOR, 2013). ${ }^{6}$

Conforme Almeida e Bastos (2008), algumas regiões, principalmente aquelas em que é evidente a concentração de empresas de determinados setores industriais, se destacam por apresentarem um desempenho econômico superior à média da economia em que se inserem. No Brasil, vários trabalhos vêm mostrando um aumento no grau de concentração da indústria nos últimos anos. Isso porque, segundo Souza (2005), o processo de concentração depende basicamente da busca de uma crescente eficiência técnica e da tendência à produção a custos sempre decrescentes. Isso

6 Esta breve revisão de literatura não busca esgotar o tema, maiores considerações, ver: Godoy (1993); Souza (2010); Souza e Cleps Júnior (2009); Fiochi et al. (2014); Kohlhepp (2010); Almeida e Bastos (2008). 
significou, e ainda significa, a formação de grandes e eficientes complexos produtivos e se origina nos mercados em que se desenvolve situações estruturalmente incompatíveis com a concorrência.

Ampliando essa discussão, para Shepherd (1999), a concentração de mercado pode suscitar uma possível má distribuição da renda gerada na economia, haja vista que as firmas que concentram a produção podem aumentar o preço bem acima do seu custo, além de reduzir a liberdade de escolha dos consumidores. Por outro lado, Siqueira (2013), citando a Escola de Chicago, salienta que uma determinada concentração de mercado pode não ser necessariamente negativa, pois sua renda pode ser redistribuída para a sociedade via novos investimentos.

Para Braga e Mascolo (1982), a concentração industrial ocorre de maneira sistemática e envolve toda a economia contemporânea, apresentando-se como um processo que ocorre no crescimento do poder de mercado sobre as atividades econômicas exercidas por empresas de grande porte. A concentração industrial é a responsável pela acumulação de riqueza, renda e produção. Para os autores, essa concentração pode ser definida, também, como um processo que incide no crescimento do poder de mercado exercido por empresas de grande porte sobre as atividades econômicas, sendo responsável pela acumulação da renda e produção, influenciando de forma direta o comportamento de seus rivais.

Em suma, Siqueira (2013, p.55) sintetiza a discussão sobre a questão da concentração, mormente para a agroindústria canavieira, com esta menção: "o crescimento das firmas pode proporcionar externalidades positivas ou negativas e, para controlá-las, as leis e os órgãos institucionais devem proporcionar mecanismos que maximizem as positivas e limitem as negativas". Não obstante, estudos devem primeiramente mostrar se está ou não ocorrendo o fenômeno da concentração de mercado, sendo esse o propósito do presente artigo - voltado para a realidade do Estado de Minas Gerais.

\section{Referencial metodológico}

Para Scherer e Ross (1990), existem basicamente três categorias de medidas de concentração: 1) medidas de concentração parciais ou sumárias, que não utilizam os dados da totalidade das empresas em operação no setor escolhido para estudo, mas apenas uma parte delas; 2) medidas de concentração positivas, determinadas unicamente em função da estrutura aparente do mercado industrial e não dependem de qualquer parâmetro comportamental, seja relativo aos produtores ou aos consumidores; e 3) medidas de concentração normativas que levam em conta, além da estrutura aparente, os parâmetros comportamentais relacionados às preferências dos produtores ou dos consumidores.

Para calcular as medidas de concentração, foram utilizados dados de produ- 
ção da cana-de-açúcar por usina/grupo7 de Minas Gerais, sendo coletados junto a SIAMIG/SINDAÇÚCAR-MG, compreendendo o período da safra 2002/2003 a 2014/2015. Para minimizar os efeitos do clima e das variações causadas por tratos culturais que se aplicam à cultura da cana-de-açúcar, foram calculadas as médias trienais móveis referentes a essas moagens.

De acordo com Hersen et al. (2011) e Chagas (2014), a decisão de utilizar somente os dados de produção de cana-de-açúcar moída, em vez dos dados de produção e/ou venda de etanol total ou açúcar total, se justifica pelo fato da moagem representar um indicador de produção potencial de açúcar, etanol, energia elétrica e outros produtos oriundos do processo de diversificação que essa agroindústria apresenta.

Diante disso, se aplicam quatro medidas de concentração positivas para a análise dos dados coletados: Razão de Concentração; Índice de Hirschmann-Herfindahl; Índice de Rosenbluth; e Entropia de Theil. Resende (1994), Hoffmann (1998), Resende e Boff (2002), Hersen et al. (2011), Almeida e Silva (2013) fazem menções ao uso dessas medidas de concentração e são as referências que sustentam os próximos parágrafos.

Primeiramente, verifica-se a participação de cada usina ou grupo sobre o total de cana-de-açúcar moída no Estado de Minas Gerais, em cada um dos períodos referentes às médias trienais, cuja participação é definida pela equação:

$$
\mathrm{y}_{\mathrm{i}}=\frac{\mathrm{x}_{\mathrm{i}}}{\mathrm{q}_{\mathrm{i}}}
$$

Em que:

$\mathrm{y}_{\mathrm{i}}=$ participação da i-ésima usina ou grupo no total de cana-de-açúcar moída em Minas Gerais;

$\mathrm{x}_{\mathrm{i}}=$ volume de cana-de-açúcar moída pela i-ésima usina/grupo;

$\mathrm{q}_{\mathrm{i}}=$ volume total de cana-de-açúcar moída em Minas Gerais.

A razão de concentração, conforme Resende (1994), é aplicada normalmente para determinar a participação de grandes empresas no mercado. Seu resultado varia de 0 a 1 , em que 0 encontra-se em situação de concorrência perfeita e 1 para uma condição de concentração intensa. Esse índice é representado pela equação:

$$
\mathrm{CR}_{\mathrm{k}}=\sum_{\mathrm{i}=1}^{\mathrm{k}} \mathrm{y}_{\mathrm{i}}
$$

É comum, quando se utiliza a razão de concentração, trabalhar com a parti-

Elucidando, foram trabalhados nesse cálculo grupos (controladores de mais de uma usina) e usina, quando esta era a única unidade empresarial de determinada pessoa jurídica. Sobre isso, ver: Shikida et al. (2008). 
cipação das quatro ou oito maiores $\left(\mathrm{CR}_{4}\right.$ e $\mathrm{CR}_{8}$, respectivamente $) 8$, o que foi feito neste trabalho, tendo em vista o número de usinas/grupos mineiros.

Salienta-se, entretanto, que as razões de concentração não levam em conta os dados da totalidade das empresas em operação para o setor pesquisado, sendo consideradas medidas de concentração parciais. A omissão das (n - k) empresas obstaculiza o uso do $\mathrm{CR}_{\mathrm{k}}$ como medida de poder de mercado (RESENDE; BOFF, 2002). Para superar essa deficiência, faz-se necessário o uso de outras medidas, sendo elas: o índice de Hirschmann-Herfindahl $(\mathrm{H})$; índice de Rosenbluth (B); e Entropia (E).

$\mathrm{O}$ índice de Hirschmann-Herfindahl $(\mathrm{H})$ é representado pela equação:

$$
\mathrm{H}=\sum_{\mathrm{i}=1}^{\mathrm{n}} \mathrm{y}_{\mathrm{i}}^{2}
$$

Em que:

$\mathrm{n}=$ número total de usinas/grupos;

$\mathrm{y}_{\mathrm{i}}=$ participação das usinas/grupos no total ao quadrado.

Para o cálculo do índice de Rosenbluth, considera-se a ordenação das usinas/ grupos de maneira que $\mathrm{p}_{1}>\mathrm{p}_{2} \ldots \mathrm{pn}$, sendo obtido por meio da equação:

$$
\mathrm{B}=\frac{1}{\left(2 \Sigma y i_{\mathrm{i}}-1\right)}
$$

O valor do índice de Hirschmann-Herfindahl, assim como o do índice de Rosenbluth, varia de $\mathrm{H}=1 / \mathrm{n}$ (divisão igualitária entre todas as empresas/grupos) até $\mathrm{H}=1$ (concentração máxima, considerando que existam empresas/grupos em Minas Gerais). Resende (1994) aponta o índice de Hirschmann-Herfindahl como uma medida de concentração apropriada para comparações intertemporais.

O Índice de Entropia de Theil (E) surgiu com base nos estudos de organização industrial sugeridos por Theil (1967). Esse coeficiente corresponde a uma medida inversa da concentração, porquanto seu valor diminui à medida que a concentração aumenta - quanto mais próximo de zero, maior o nível de concentração. Nesse índice, é levado em conta o Market-share de cada indústria perante o uso de logaritmo, como colocado na equação:

$$
\mathrm{E}=\sum_{\mathrm{i}=1}^{\mathrm{n}} \mathrm{y}_{1} \ln \frac{1}{\mathrm{y}_{\mathrm{i}}}
$$

Assim como em Hersen et al. (2011), este trabalho procura analisar as mudanças estruturais mais recentes ocorridas no setor da cana-de-açúcar diante de todas as transformações sofridas pelo setor após o início do século XXI. A próxima seção apresenta os resultados da discussão desses dados.

8 Sobre isso, ver: Vian et al. (2008) e Hersen et al. (2011). 


\section{Resultados e discussões}

Os indicadores de concentração calculados para a produção canavieira em Minas Gerais apontam para continuidade no processo de concentração, identificado no estudo de Hersen et al. (2011), até a média trienal 2003-2004/2005-2006. Porém, baseando-se na média trienal de 2004-2005/2006-2007, percebe-se um movimento de inversão no processo de concentração (houve apenas uma exceção nessa tendência, 2006-2007/2008-2009), que se acentua até a média trienal das safras 2010-2011/2012-2013. Já nas duas safras seguintes, o mercado volta a apresentar crescimento da concentração, conforme a Tabela 1.

Tabela 1 - Índices de concentração da produção canavieira no estado de Minas Gerais - safras 2002/2003 a 2014/2015

\begin{tabular}{|c|c|c|c|c|c|c|}
\hline Safras* & $\begin{array}{c}\text { Razão de } \\
\text { concentra- } \\
\text { ção } C R_{4}\end{array}$ & $\begin{array}{c}\text { Razão de } \\
\text { concentra- } \\
\text { ção } C R_{8}\end{array}$ & $\begin{array}{c}\text { Índice de } \\
\text { Hirschmann } \\
\text { - Herfindahl } \\
\text { HH }\end{array}$ & $\begin{array}{c}\text { Índice de } \\
\text { Rosenbluth } \\
B\end{array}$ & $\begin{array}{l}\text { Entropia } \\
\text { de distri- } \\
\text { buição } E\end{array}$ & $\begin{array}{c}\text { Número de } \\
\text { usinas / grupos }\end{array}$ \\
\hline $02-03 / 04-05$ & $56,32 \%$ & $75,19 \%$ & 0,1203 & 0,1009 & 2,5054 & 19 \\
\hline $03-04 / 05-06$ & $56,39 \%$ & $74,50 \%$ & 0,1230 & 0,1002 & 2,4977 & 19 \\
\hline 04-05/06-07 & $55,44 \%$ & $74,07 \%$ & 0,1196 & 0,0964 & 2,5408 & 21 \\
\hline $05-06 / 07-08$ & $54,64 \%$ & $72,96 \%$ & 0,1170 & 0,0916 & 2,5932 & 24 \\
\hline 06-07/08-09 & $55,83 \%$ & $73,42 \%$ & 0,1134 & 0,0890 & 2,6458 & 28 \\
\hline 07-08/09-10 & $54,55 \%$ & $70,61 \%$ & 0,1037 & 0,0823 & 2,7245 & 29 \\
\hline 08-09/10-11 & $51,76 \%$ & $66,39 \%$ & 0,0915 & 0,0699 & 2,8787 & 35 \\
\hline $09-10 / 11-12$ & $48,33 \%$ & $62,09 \%$ & 0,0814 & 0,0629 & 2,9781 & 35 \\
\hline $10-11 / 12-13$ & $47,75 \%$ & $60,63 \%$ & 0,0786 & 0,0601 & 3,0139 & 36 \\
\hline $11-12 / 13-14$ & $47,95 \%$ & $62,59 \%$ & 0,0786 & 0,0609 & 3,0068 & 36 \\
\hline $12-13 / 14-15$ & $50,50 \%$ & $65,87 \%$ & 0,0843 & 0,0685 & 2,9132 & 34 \\
\hline
\end{tabular}

Fonte: Dados da Pesquisa

*Médias trienais móveis de moagem de cana-de-açúcar em Minas Gerais.

Pormenorizando a análise dos índices de concentração da produção canavieira em Minas Gerais, verifica-se que o $\mathrm{CR}_{4}$ diminuiu em 10,35\% no período analisado, enquanto o $\mathrm{CR}_{8}$ apresentou uma redução mais acentuada $12,40 \%$, ou seja, as grandes agroindústrias perderam menos mercado em relação às médias. Cabe ressaltar que, apesar da tendência de desconcentração, considerando um longo prazo, é possível visualizar uma tendência de concentração das usinas no curto prazo, deflagrada a partir do período 2011-2012/2013-2014.

Ademais, o trabalho de Vian et al. (2008) mostra alguns padrões de referência 
para avaliar se o mercado é muito ou pouco concentrado em termos da agroindústria canavieira. No caso alagoano, por exemplo, o $\mathrm{CR}_{4}$ foi de 25,24\% em 1993 para 32,06\% em 2003, e o $\mathrm{CR}_{8}$ foi de 44,80\% em 1993 para 51,49\% em 2003, sendo que o movimento concentracionista em Alagoas confirmou-se com os demais indicadores de concentração (HH e B cresceram, e E reduziu). Percebe-se, considerando os dados de Minas Gerais, que, embora essa realidade tenha apresentado vicissitudes no período analisado, houve um crescimento da concentração com base nas últimas safras analisadas.

Parte do movimento de desconcentração nessa agroindústria canavieira pode ser justificada pelo aumento no número de usinas/grupos, passando de 19 na safra de 2002-2003/2004-2005 (baseado no cálculo das médias trienais realizadas para este trabalho), para 36 em 2010-2011/2012-2013, um crescimento de 89,47\%, com maior número de empresa/grupos registrado no período em análise. Porém, no último período de análise, apenas 34 estavam em operação, ou seja, houve crescimento de 78,95\% no número de usinas/grupos em se tratando dos extremos do período em análise.

Dessa forma, identificou-se uma relação inversa entre os níveis de concentração e número de empreendimentos, pois, ao mesmo tempo em que o número de agroindústrias diminui, houve uma tendência de maior concentração, isso porque menos usinas/grupos ficam “responsáveis” pela moagem. Esse movimento de redução das empresas em operação está relacionado com a situação de crise no complexo canavieiro nacional, conforme Nascimento (2014). Das 439 usinas instaladas no País (cadastradas em 2009), apenas 343 estavam em operação na safra 2013-2014.

Outrossim, o crescimento significativo da agroindústria canavieira em Minas Gerais foi privilegiado pelo movimento expansionista do setor em direção ao bioma cerrado, por apresentar condições edafoclimáticas favoráveis e custo da terra atrativo para o setor. Para Vian (2003), essa área geográfica abrange desde o Oeste Paulista até Goiás, Mato Grosso, Mato Grosso do Sul, Minas Gerais, Maranhão, Piauí e Bahia. Outro fator que privilegia a expansão do setor sucroenergético no estado é sua posição geográfica, pois Minas Gerais faz divisa com São Paulo, maior produtor do País, o que favorece a logística.

Os planos de financiamentos nacionais e internacionais para instalação e renovação dos parques industriais e o ambiente de otimismo criado no período de 2004-2008 contribuíram também para o crescimento no número de empresas e da produção no estado (SANTOS, 2016). Porém, após a crise financeira de 2008, o crédito ficou restrito, principalmente o internacional, fato que dificultou a rolagem das dívidas contraídas pelas indústrias. $\mathrm{O}$ crédito interno também começou a ser restringido a partir de 2011, pois o maior operador nacional, BNDES (Banco Nacional de Desenvolvimento Econômico e Social), reduziu significativamente o volume de crédito liberado para o setor, favorecendo diversas falências e, consequentemente, colaborando para o desencadeamento de um novo processo de concentração no estado, conforme já observado (SANTOS et al., 2016). 
De acordo com Santos (2016), outros fatores contribuíram para o desencadeamento da crise, tais como: I) O desequilíbrio no mercado de etanol causado pelo controle estatal de preços da gasolina, fazendo com que o etanol perdesse competitividade, contribuindo de forma crucial para a crise deflagrada a partir do ano de 2010; II) a elevação do custo do crédito e a redução de margens, após a crise financeira de 2008; e III) elevação dos custos de produção agrícola.

Esse processo de crise, aliado à restrição de crédito, impactou em uma redução da produção nos anos seguintes, como mostra a Tabela 2. Tanto em Minas como no restante do Brasil, houve uma retração no volume de produção de cana-de-açúcar da safra de 2011/2012 para 2012/2013, tendo como consequência uma redução na produção de etanol, o que, como foi descrito anteriormente, resultou em um número menor de usinas, favorecendo o aumento da concentração da produção.

Tabela 2 - Produções de cana-de-açúcar, açúcar e etanol total (anidro e hidratado) em Minas Gerais e no restante do Brasil - safras 2002/2003 a 2014/2015

\begin{tabular}{|c|c|c|c|c|c|c|c|c|c|}
\hline \multirow{2}{*}{ Safra } & \multicolumn{3}{|c|}{$\begin{array}{c}\text { Produção cana-de-açúcar (mil } \\
\text { toneladas) }\end{array}$} & \multicolumn{3}{|c|}{$\begin{array}{c}\text { Produção açúcar (mil tone- } \\
\text { ladas) }\end{array}$} & \multicolumn{3}{|c|}{ Produção de etanol (mil m³) } \\
\hline & $\begin{array}{l}\text { Minas } \\
\text { Gerais }\end{array}$ & Brasil & $\mathrm{MG} / \mathrm{BR}$ & $\begin{array}{l}\text { Minas } \\
\text { Gerais }\end{array}$ & Brasil & $\begin{array}{l}\mathrm{MG} / \\
\mathrm{BR}\end{array}$ & $\begin{array}{l}\text { Minas } \\
\text { Gerais }\end{array}$ & Brasil & $\% \mathrm{MG} / \mathrm{BR}$ \\
\hline $2002 / 2003$ & 15.600 & 320.650 & $4,9 \%$ & 1.093 & 22.567 & $4,8 \%$ & 636 & 12.623 & $5,0 \%$ \\
\hline $2003 / 2004$ & 18.608 & 358.762 & $5,2 \%$ & 1.347 & 24.919 & $5,4 \%$ & 772 & 14.736 & $5,2 \%$ \\
\hline 20042005 & 21.532 & 385.199 & $5,6 \%$ & 1.665 & 26.685 & $6,2 \%$ & 793 & 15.389 & $5,2 \%$ \\
\hline $2005 / 2006$ & 24.541 & 385.129 & $6,4 \%$ & 1.742 & 25.823 & $6,7 \%$ & 959 & 15.821 & $6,1 \%$ \\
\hline $2006 / 2007$ & 29.034 & 427.658 & $6,8 \%$ & 1.912 & 29.988 & $6,4 \%$ & 1.291 & 17.844 & $7,2 \%$ \\
\hline $2007 / 2008$ & 35.723 & 495.723 & $7,2 \%$ & 2.118 & 31.026 & $6,8 \%$ & 1.775 & 22.527 & $7,9 \%$ \\
\hline $2008 / 2009$ & 42.634 & 569.216 & $7,5 \%$ & 2.208 & 31.049 & $7,1 \%$ & 2.181 & 27.526 & $7,9 \%$ \\
\hline $2009 / 2010$ & 50.573 & 602.193 & $8,4 \%$ & 2.685 & 32.956 & $8,1 \%$ & 2.251 & 25.691 & $8,8 \%$ \\
\hline 2010/2011 & 54.629 & 620.409 & $8,8 \%$ & 3.244 & 38.006 & $8,5 \%$ & 2.558 & 27.376 & $9,3 \%$ \\
\hline $2011 / 2012$ & 49.741 & 559.215 & $8,9 \%$ & 3.238 & 35.925 & $9,0 \%$ & 2.084 & 22.682 & $9,2 \%$ \\
\hline $2012 / 2013$ & 51.759 & 588.478 & $8,8 \%$ & 3.418 & 38.246 & $8,9 \%$ & 1.994 & 23.226 & $8,6 \%$ \\
\hline $2013 / 2014$ & 61.042 & 652.956 & $9,3 \%$ & 3.411 & 37.562 & $9,1 \%$ & 2.657 & 27.541 & $9,6 \%$ \\
\hline $2014 / 2015$ & 59.321 & 632.127 & $9,4 \%$ & 3.267 & 35.548 & $9,2 \%$ & 2.727 & 28.394 & $9,6 \%$ \\
\hline
\end{tabular}

Fonte: UNICA, 2016.

Apesar da crise do setor sucroalcooleiro, que culminou na falência de algumas empresas, incorporações, fusões e novos arranjos de integração, o setor no Estado de Minas Gerais demonstrou crescimento conforme a Tabela 2, além de apresentar aumento na participação relativa do total de produção no País, tanto em termos de produção quanto nos principais produtos: açúcar e etanol.

Considerando a produção de cana-de-açúcar em Minas Gerais, houve um au- 
mento de $280,26 \%$ no volume total, com destaque para produção de etanol, que passou de $636\left(\mathrm{mil} \mathrm{m}^{3}\right)$ em 2002/03 para 2.727 (mil m³) em 2014/2015. Esse aumento da produção frente ao aumento da concentração e redução do número de empresas demonstrou que as pequenas indústrias sofreram mais em relação às grandes durante a crise, ou seja, conseguiram sobreviver as empresas com maior nível de competitividade.

Segundo Santos et al. (2016), a crise atinge especialmente empresas de pequeno porte, em razão das baixas margens operacionais, demora na adoção de tecnologias, falhas na gestão e planejamento, atrasos na recuperação de canaviais e na mecanização da colheita. Sendo assim, os grupos maiores incorporam as empresas com dificuldade, em detrimento de estratégia visto a dominar o mercado, atitude essa que tende a concentrar ainda mais o mercado de cana-de-açúcar.

Os indicadores - índice de Hirschmann-Herfindahl, índice de Rosenbluth e Entropia (Gráfico 1) - corroboram a indicação dos índices $\mathrm{CR}_{4}$ e $\mathrm{CR}_{8}$, nos quais houve uma redução da concentração ocorrida ao longo do período analisado. Porém, a partir da safra 2011-2012/2013-2014, o mercado sucroalcooleiro em Minas Gerais voltou a se concentrar em termos de volume de moagem. Considerando os limites extremos, ou seja, de 2002/2003-2004/2005 a 2012/2013-2014/2015, a redução no índice de Hirschmann-Herfindahl e de Rosenbluth foi de, respectivamente, $29,9 \%$ e $32,2 \%$, e índice de entropia - frisa-se que se trata de uma medida inversa de concentração - teve uma variação positiva de $16,3 \%$.

Gráfico 1 - Índices de concentração da produção canavieira no estado de Minas Gerais - safras 2002/2003 a 2014/2015

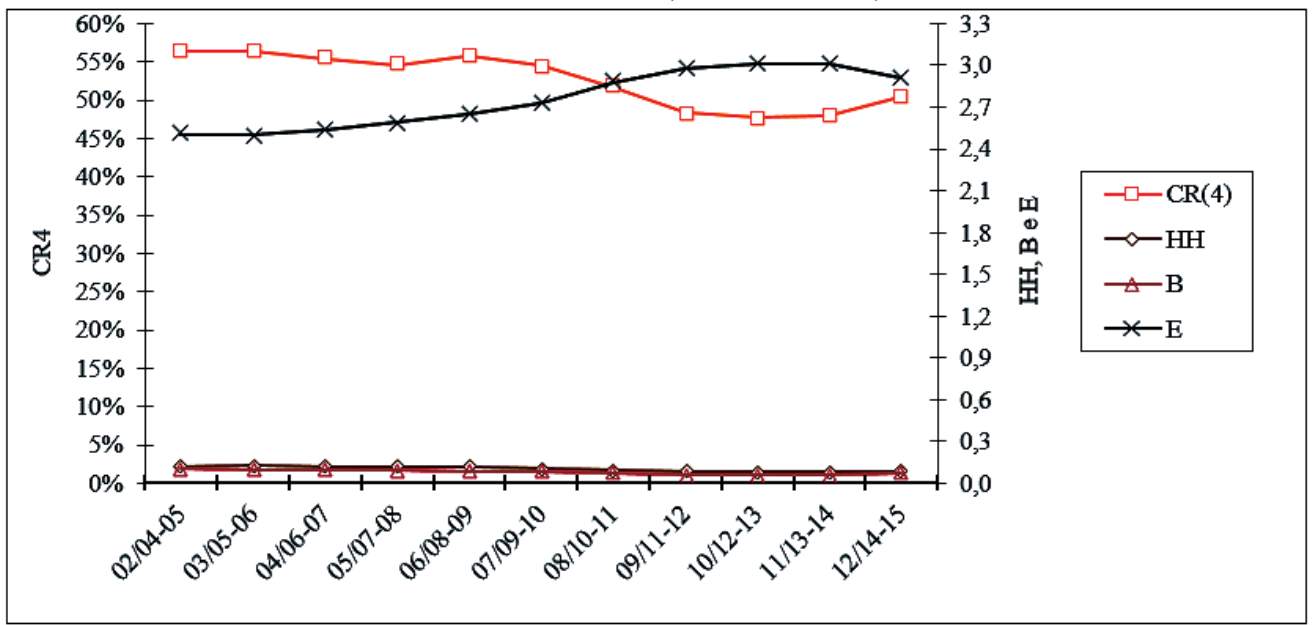

Fonte: Dados da Pesquisa

Destaca-se que, tomando-se por base a média trienal 2007-2008/2009-2010, não foi observada posição dominante de qualquer empresa. Anteriormente, duas 
empresas configuraram-se com participação de mercado superior a 20\%, caracterizando um elevado poder de mercado detido por ambas. Cabe ressaltar que posição dominante é definida quando uma empresa detém pelo menos $20 \%$ de participação no mercado, controlando parcela fundamental desse. Adicionalmente, o $\mathrm{CR}_{4}$ permaneceu abaixo do limite sugerido de $60 \%$, que ofereceria considerável oportunidade para comportamento oligopolístico. A existência de estruturas concentradas de mercado favorece a adoção de práticas anticompetitivas pelas empresas com maior poder de mercado (LEME, 1999; MELLO, 2002; CADE, 2007; VIAN et al., 2008).

\section{Considerações finais}

Objetivou-se, neste trabalho, verificar a concentração agroindustrial canavieira do Estado de Minas Gerais durante as safras 2002/2003 a 2014/2015, utilizando-se, como instrumental de análise, as principais medidas de concentração $\left(\mathrm{CR}_{4} \mathrm{e}\right.$ $\mathrm{CR}_{8}$, os índices de Hirschmann-Herfindahl, Rosenbluth e Entropia).

O período de início da análise apresentava um quadro de prosperidade ao setor sucroalcooleiro, em virtude do início da utilização de carros flex-fuel, o que gerou incentivo para a expansão dos canaviais. Destarte, culminou em um aumento de preço e de produção nas safras subsequentes a 2002/2003. Assim, obteve-se um grau maior de desconcentração da produção, o que pode ser visto nos resultados de todos os indicadores utilizados.

$\mathrm{O} \mathrm{CR}_{4}$ mostrou uma redução significativa, apontando uma melhor condição de competitividade no mercado, além disso, o $\mathrm{CR}_{1}$, a partir do período de análise iniciado em 2007-2008/2009-2010, nenhuma empresa apresentou posição dominante de mercado. Isso mostra que, no período, o mercado apresentava condições favoráveis para o desenvolvimento e criação de grupos menores. Os demais indicadores corroboraram os resultados do $\mathrm{CR}_{4}$.

A partir das safras 2008/2009, houve uma redução no crédito, que, aliado a outros fatores, impactaram na produção de cana-de-açúcar principalmente na produção de etanol no Estado de Minas Gerais nos anos posteriores, realidade traduzida nos resultados obtidos pelos indicadores, pois, após uma queda do $\mathrm{CR}_{4}$, a partir do período 2010-2011/2012-2013, foram identificados pequenos aumentos nesse indicador, principalmente no último período de análise. Além disso, a partir do período 2011-2012/2013-2014, o mercado sucroalcooleiro em Minas Gerais voltou a concentrar em termos de volume de moagem.

Dessa forma, pode-se dizer que os resultados do trabalho corroboram o que foi observado em outros trabalhos que abordam o tema. Também mostrou compatibilidade com a flutuação do volume de produção, aliado aos fatores que impactaram negativa ou positivamente o setor, deflagrando movimentos de concentração ou desconcentração da produção no estado.

Por último, mas não menos importante, sugere-se a implementação de mais 
pesquisas para refletir sobre os aspectos caracterizadores da produção canavieira em Minas Gerais, assim como de outros estados brasileiros, para averiguar não só elementos acerca da produção, mas também da importância desse segmento para a geração do etanol e da bioeletricidade, que colocam o Brasil na vanguarda do planeta no campo da substituição de petróleo.

\section{Referências}

ASSOCIAÇÃO DE PRODUTORES DE BIOENERGIA DO ESTADO DO PARANÁ (ALCOPAR). Estatísticas. Disponível em: <http://www.alcopar.org.br/ estatisticas >. Acessado em 07-12-2016.

ALMEIDA, F. A. de; SILVA, A. S. B. da Concentração industrial: uma análise à luz do setor de transformação mineiro. In. Encontro Científico Sul Mineiro de Administração, Contabilidade e Economia. Anais... 5a ed. 2013.

ALMEIDA, B. B. M. M.; BASTOS, S. Q. A. Aglomerações industriais em Minas Gerais: identificação através de distintas bases de dados. In: Encontro Nacional da Associação Nacional de Pós-Graduação em Economia - ANPEC, Anais.... 2008.

BACCARIN, J. G., GEBARA, J. J., FACTORE, C. O. Concentração e integração vertical do setor sucroalcooleiro do Brasil, entre 2000 e 2007. Informações Econômicas, São Paulo, v.39, n.3, p.17-29, mar. 2009.

BANCO MUNDIAL (World Bank). Disponível em: < http://www.worldbank. org/pt/country/brazil>.Acessado em 07-12-2016.

BRAGA, H. C.; MASCOLO, J. L. Mensuração da concentração industrial no Brasil. Pesquisa e Planejamento Econômico. v. 12, n. 2, p.399-354, ago., 1982.

CADE - CONSELHO ADMINISTRATIVO DE DEFESA ECONÔMICA. Guia Prático do CADE: a defesa da concorrência no Brasil. 3. ed. São Paulo: CIEE, 2007.

CHAGAS, R. de S. B. Análise da estrutura agroindustrial canavieira a partir dos processos de diversificação industrial e inovações verificados no período de 2000 a 2010. Dissertação (mestrado) - Universidade Federal do Rio de Janeiro, Instituto de Economia, Programa de Pós-Graduação em Políticas Públicas, Estratégias e Desenvolvimento, 2014. 
DERAL - DEPARTAMENTO DE ECONOMIA RURAL. Disponível em http:// www.agricultura.pr.gov.br/modules/conteudo/conteudo.php? conteudo $=195$. Acessado em 10-03-2016.

GODOY, M. M. Engenhos do dezenove: a agroindústria da cana-de-açúcar em Minas Gerais. Anais do IV Seminário Nacional de História da Ciência e da Tecnologia, pp. 125/132. São Paulo: FAPEMIG - Anna Blume - Nova Stella, 1993.

FIOCHI, V. G.; TEIXEIRA, L. DE A.; DE PAULA, G. G. gerenciamento de resíduos da agroindústria canavieira e cogeração de energia na região do Triângulo Mineiro, Minas Gerais. VII Congresso Brasileiro de Geógrafos. Anais do VII CBG. Vitória - ES, 2014.

HERSEN, A.; SHIKIDA, P. F. A.; DAHMER, V. de S. Concentração na agroindústria canavieira mineira durante as safras 1996/1997 a 2005/2006. Organizações Rurais E Agroindustriais, Lavras, v. 13, n. 3, p.303-316, 2011.

HOFFMANN, R. Distribuição de renda: medidas de desigualdade e pobreza. São Paulo: EDUSP, 1998. 280 p.

LEME, M. F. P. Concentração e internacionalização de capital na indústria brasileira de alimentos. Dissertação (Mestrado) - Escola Superior de Agricultura "Luiz de Queiroz”, Piracicaba, 1999.

KOHLHEPP, G. Análise da situação da produção de etanol e biodiesel no Brasil. Estudos Avançados, São Paulo, v. 24, n. 68, 2010, p. 223 - 252. crossrefhttps://doi. org/10.1590/S0103-40142010000100017

LIMA, J. C. de S. A intervenção governamental no setor açucareiro: ênfase à problemática do subsídio de equalização. Tese (Doutorado) - Faculdade de Economia e Administração, Universidade de São Paulo, São Paulo, 1992, 118 p.

MELLO, M. T. L. Defesa da Concorrência. In: KUPFER, D.; HASENCLEVER, L. (Orgs.). Economia Industrial: fundamentos teóricos e práticos no Brasil. Rio de Janeiro: Campus, 2002,p. 485-514.

MELLO, F. O. T.; PAULILLO, L. F. Recursos de poder e capacidade dinâmica de aprendizado dos atores sucroalcooleiros paulistas pós-desregulamentação estatal. Informações Econômicas, v. 35, n. 6, p. 17-29, 2005. 
NASCIMENTO, D. Crise nas usinas chega à Justiça. Revista RPA Neres, ano 13, n. 164, p.6-13, out. 2014. Disponível em: <http://goo.gl/jKTEwf >.Acessado em 10-06-2016.

PAUliLlO, L. F.; VIAN, C. E. de F.; SHIKIDA, P. F. A.; MELLO, F. T. Álcool combustível e biodiesel no Brasil: quo vadis? Revista de Economia e Sociologia Rural, Brasília, v.45, n.03. p.531-565, Jul./Set., 2007.

PAUliLlO, L.F; SOARES, S. S; FELTRE, C; MARQUES, D. S. P; VIAN, C. E. F. As Transformações e aos desafios do encadeamento produtivo do etanol no Brasil. In: SANTOS, G. R. dos (Org.). Quarenta anos de etanol em larga escala no Brasil: desafios, crises e perspectivas. Brasília: Ipea, 2016.p.187-224.

RESENDE, M. Medidas de concentração industrial: uma resenha. Análise Econômica, São Paulo, ano 11, p.24-33, mar./set. 1994.

SANTOS, G. R. dos (Org). Quarenta anos de etanol em larga escala no Brasil: desafios, crises e perspectivas. Brasília: IPEA, 2016. 315 p.

SANTOS, G. R. dos; GARCIA, E. A.; SHIKIDA, P. F. A.; RISSARDI JÚNIOR, D. J. A agroindústria canavieira e a produção de etanol no Brasil: características, potenciais e perfil da crise atual. In: SANTOS, G. R. dos (Org). Quarenta anos de etanol em larga escala no Brasil: desafios, crises e perspectivas. Brasília: IPEA, 2016.p.17-45.

SCHERER, F.; M; ROSS, D. Industrial market structure and economic performance. Boston: Houghton M. Company, 3 ed, 1990.

SHEPHERD, W. G. The economics of industrial organization. New York: Waveland, 1999.

SHIKIDA, P. F. A. A evolução diferenciada da agroindústria canavieira no Brasil de 1975 a 1995. 1997. 191 f. Tese (Doutorado) - Escola Superior de Agricultura Luiz de Queiroz, Universidade de São Paulo, Piracicaba.

SHIKIDA, P. F. A. Evolução e fases da agroindústria canavieira no Brasil. Revista de Política Agrícola. n. 4. p.43-57, Out./Nov./Dez, 2014.

SHIKIDA, P. F. A.; VIAN, C. E. de F.; LIMA, R. A. de S.; DAHMER, V. de S. Concentração na agroindústria canavieira paranaense pós-desregulamentação setorial. Informações Econômicas, São Paulo (SP), v.38, n.9, p.55-67, Set. 2008. 
SIAMIG - SINDICATO DA INDÚSTRIA DE FABRICAÇÃO DO ÁLCOOL NO ESTADO DE MINAS Gerais. Perfil da produção. Disponível em:http://www. siamig.com.br/cache/Documentos/perfilproducaosite.pdf. Acessado em 10-032016.

SIQUEIRA, P. H. de L. Estratégias de crescimento e de localização da agroindústria canavieira brasileira e suas externalidades. Tese. Doutorado em Dinâmica e Gestão de Cadeias Produtivas, Universidade Federal de Lavras, 2013. 189 p.

SIQUEIRA, P. H. de L.; CASTRO JÚNIOR, L. G. Determinantes da localização da agroindústria canavieira nos municípios de Minas Gerais. Revista de Economia e Sociologia Rural - RESR, Piracicaba-SP, v. 51, n. 2, p.309-330, Abr/Jun 2013.

SOUZA, A. G. CLEPS JÚNIOR, J. O desenvolvimento da agroindústria canavieira no Triângulo Mineiro e seus impactos sobre mão-de-obra e a produção de alimentos. In. XIX Encontro Nacional de Geografia Agrária. Anais... São Paulo, 2009, p.1-16.

SOUZA, A. G. Impactos da expansão da cana-de-açúcar no município de Campo Florido (MG). In: Encontro Anual dos Geógrafos. Anais... Porto Alegre - RS, 2010.

THEIL, H. Economics and information theory. Amsterdam, North-Holland, 1967.

UNICA - UNIÃO DA INDÚSTRIA DE CANA-DE-AÇÚCAR. Base de dados (UNICADATA). Disponível em: http://www.unicadata.com.br/index. php? idioma=1. Acessado em 16-02-2016.

VIAN, C. E. de F. Agroindústria canavieira: estratégias competitivas e modernização. Campinas: Átomo, 2003.

VIAN, C. E. de F.; LIMA, A. A.; LIMA, R. A. de S. Estudo de impacto econômico para o setor agroindustrial canavieiro paulista e algoano: conjuntura e agenda de pesquisa. Revista Econômica do Nordeste, v. 39, p. 518-539, 2008.

Recebido em 14.09.16

Aprovado em 24.02.17 